\title{
MODEL MATEMATIS TURBIN PELTON DENGAN MENGGUNAKAN BAHASA PEMROGRAMAN JAVA
}

\author{
Gunarto $^{1}$, Asrul Abdullah ${ }^{2}$, Doddy Irawan ${ }^{3}$ \\ ${ }^{1,2,3}$ Fakultas Teknik Universitas Muhammadiyah Pontianak \\ Sur-ell1: guncici75@gmail.com \\ Sur-el²: asrul.abdullah@unmuhpnk.ac.id \\ Sur-el ${ }^{3}$ : irawan.doddy@unmuhpnk.ac.id
}

\begin{abstract}
Abstrak
Penelitian ini bertujuan merancang suatu model matematis turbin pelton dengan menggunakan bahasa pemrograman Java pada peralatan praktikum turbin pelton di Laboratorium Teknik Universitas Muhammadiyah Pontianak. Selain itu, program rumus sederhana ini diharapkan dapat membantu mahasiswa dalam membuat laporan praktikum turbin pelton tanpa mengesampingkan perhitungan secara teoritisnya. Metode yang akan dilakukan dalam penelitian ini adalah menggunakan incremental development method, dengan 4 (empat) tahapan. Tahapan pertama adalah merancang atau membuat interface dari model matematis perhitungan turbin pelton ini. Tahapan kedua membuat script dengan menggunakan bahasa pemrograman Java. Tahapan ketiga melakukan pengujian dengan program ini. Dan terakhir penggunaan program. Hasil dari penelitian, program sederhana ini dapat berjalan dengan baik meskipun masih banyak kekurangannya. Penggunaannya masih terbatas sehingga masih perlu pengembangan sehingga kedepannya dapat dipergunakan secara global.
\end{abstract}

Kata kunci: model, matematis, pemrograman, java, interface

\begin{abstract}
This study aims to design a mathematical model of Pelton turbine using Java programming language on Pelton turbine practicum equipment at the Technical Laboratory of University Muhammadiyah of Pontianak. In addition, this simple formula program is expected to assist students in preparing the Pelton turbine practice report without ruling out theoretical calculations. The method that will be done in this research is using incremental development method, with 4 (four) stages. The first stage is to design or create an interface of mathematical models of calculation of this pelton turbine. The second stage creates the script using Java programming language. The third stage of testing with this program. And the last use of the program. The results of the study, this simple program can run well although there are still many shortcomings. Its use is still limited so it still needs development so that the future can be used globally.
\end{abstract}

Keywords: model, mathematical, programming, java, interface

\section{PENDAHULUAN}

Saat ini Indonesia sudah berada pada era Masyarakat Ekonomi Asean (MEA) yang menandakan persaingan di kawasan ASEAN sedang berlangsung termasuk dalam bidang pendidikan. Sumber daya alam yang melimpah tidak lagi menjamin memenangkan persaingan manakala sumber daya manusianya lemah. Seiring berjalannya waktu, TIK (Teknologi Informasi dan Komunikasi) berkembang sangat pesat. Hal ini membuktikan bahwa peran manusia dalam pengembangan TIK sudah mencapai taraf yang diinginkan, apakah hal ini cukup? Jelas belum cukup, mengingat belum tercapainya pemerataan pengembangan TIK kedalam aspek-aspek kehidupan. Kaitannya dengan hal tersebut, masih banyak yang harus dipelajari untuk mengembangkan dan mensosialisasikan TIK dengan harapan manusia dapat memperoleh taraf kehidupan yang lebih baik.

Pelaksanaan pembelajaran di bidang teknik mesin sebenarnya tidak bisa hanya melalui teori di dalam kelas. Oleh karena itu pembelajaran yang baik dibidang keteknikan 
adalah menambah pembelajaran berbasis laboratorium dengan melakukan praktikum. Salah satu praktikum yang dilakukan mahasiswa Fakultas Teknik Program Studi Teknik Mesin Universitas Muhammadiyah Pontianak adalah pengujian performance turbin pelton.

Mahasiswa yang sudah melakukan praktikum, sesuai dengan aturan harus membuat laporan hasil praktikum tersebut. Biasanya didalam laporan praktikum mahasiswa harus mengolah data yang sudah diperolehnya untuk dihitung ke dalam rumus agar diketahui berbagai variabel yang ingin diketahui. Dalam perhitungan teroritis ini kebanyakan mahasiswa masih menggunakan perhitungan secara manual dan hasilnya baru dimasukkan lagi ke dalam tabel satu persatu, sehingga menyebabkan banyak sekali mahasiswa yang sering terlambat dalam pengumpulan laporan praktikum tersebut.

Hal ini lah yang mendasari munculnya ide untuk membuat model matematis perhitungan turbin pelton dengan menggunakan bahasa pemrograman Java. Program sederhana ini diharapkan dapat mengatasi permasalahan yang ada saat ini, dimana mahasiswa hanya input data dan hasil akhir mahasiswa sudah bisa memperoleh output berupa tabel sesuai dengan data yang dimasukan.

\section{DASAR TEORI}

\section{Bahasa Pemrograman Java}

James Gosling pada tahun 1995 menciptakan Bahasa pemrograman Java yang dirilis oleh Sun Microsystem Java Platform. Sebenarnya sintaks Java merupakan hasil penurunan $\mathrm{C}$ dan $\mathrm{C}++$. Di dalam $\mathrm{C}$ dan $\mathrm{C}++$ sintaksnya agak lebih rumit dibandingkan dengan Java. Java memiliki sintaks (struktur bahasa) yang lebih simple, ketat dan mempunyai akses ke OS yang lebih terbatas. Hal ini karena Java ditujukan sebagai bahasa pemrograman yang cukup sederhana untuk dipelajari dan mudah dibaca.

Dalam penulisannya bahasa pemrograman Java menggunakan file dengan ekstensi .java (dot java), dimana selanjutnya ekstensi tersebut dicompile menjadi fle .class (dot class). File .class merupakan bytecode, dimana file ini dapat dijalankan di semua Java Virtual Machine, tanpa melihat OS-nya ataupun arsitektur processornya. Java adalah bahasa yang ditujukan untuk semua kebutuhan, concurent, berbasis class, object oriented serta didesain agar tidak tergantung terhadap lingkungan dimana aplikasi dijalankan (OS dan processor).
Secara umum Java Platform untuk tujuan pengembangan dibagi menjadi 3 profile :

1. Java SE (Java Standard Edition), Java yang bisa digunakan di PC maupun server

2. Java ME (Java Micro Edition), Java yang bisa digunakan di handphone, tablet dan smartphone

3. Java EE (Java Enterprise Edition), Java yang digunakan untuk pengembangan web dan untuk aplikasi-aplikasi besar

Dalam membuat dan menjalankan program Java, agar dapat berjalan dengan baik maka diperlukan instalasi Java Development Kit (JDK). Java Development Kit (JDK) adalah suatu perangkat lunak yang digunakan untuk proses menterjemahkan (compile) dari kode Java ke bytecode sehingga dapat dimengerti dan dijalankan oleh Java Runtime Environment (JRE). Sedangkan untuk membuat program atau aplikasi dapat digunakan suatu perangkat lunak yang bernama NeatBeans IDE.

\section{Tipe Data} berikut:

Tipe data yang ada di Java sebagai

Tabel 1 Tipe data

\begin{tabular}{ll}
\hline Tipe data & Keterangan \\
\hline boolean & false atau true \\
Char & Karakter \\
Byte & $-128-127$ \\
Short & $-32768-32767$ \\
Int & $-2147483648-2147483647$ \\
long & $-9223372036854775808-$ \\
& 9223372036854775808 \\
Double & $4.9 \mathrm{E}-324-$ \\
& $1.7976931348623157 \mathrm{E} 308$ \\
Float & $1.4 \mathrm{E}-45-3.4028235 \mathrm{E} 38$ \\
\hline
\end{tabular}

Variabel

Variabel digunakan untuk menampung suatu data.Di dalam variabel terdapat tipe data ataupun tipe class, sehingga variabel harus ada kelas.

\section{Operator}

Operator merupakan karakter khusus yang dapat digunakan untuk memperoleh suatu nilai. Dengan istilah lain dalam bahasa pemrograman, operator digunakan untuk suatu perhitungan suatu nilai. Berikut adalah lambang dari berbagai operator.

\section{Tabel 2 Operator}

\begin{tabular}{ll}
\hline Operator & Keterangan \\
\hline+ & Penjumlahan \\
- & Pengurangan \\
$*$ & Perkalian
\end{tabular}




\begin{tabular}{ll}
$/$ & Pembagian \\
$\%$ & Sisa Pembagian \\
\hline
\end{tabular}

Perangkat lunak (software) yang digunakan untuk membuat program ini adalah NeatBeans IDE. Berikut tampilan dari perangkat ini.

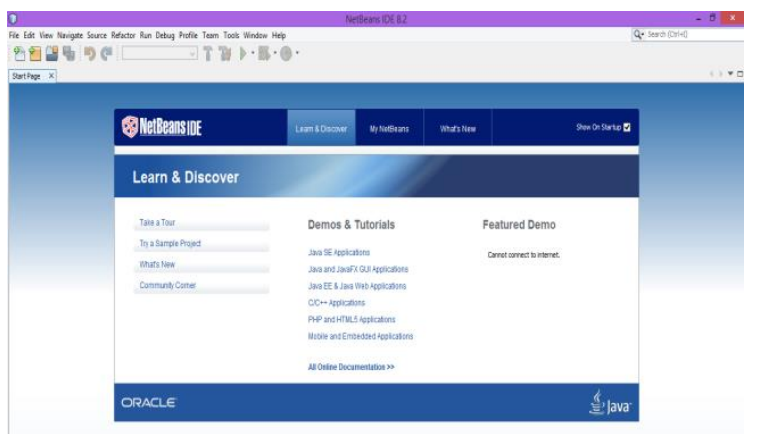

Gambar 1 Tampilan Awal NeatBeans IDE

\section{METODE PENELITIAN}

Metode yang akan dilakukan dalam penelitian ini adalah menggunakan incremental development method, dengan 4 (empat) tahapan.

1. Tahapan pertama adalah merancang atau membuat interface dari model matematis perhitungan turbin pelton ini.

2. Tahapan kedua membuat script dengan menggunakan bahasa pemrograman Java.

3. Tahapan ketiga melakukan pengujian terhadap program yang telah dibuat,dan

4. Tahapan keempat penggunaan program.

Di bawah ini adalah rumus-rumus yang digunakan dalam pengujian turbin pelton dengan menggunakan bahasa pemrograman Java.

1. Debit air $(\mathrm{Q})$

$\boldsymbol{Q}=\boldsymbol{V}$. $\boldsymbol{A}$.

Dimana:

$$
\begin{aligned}
\mathrm{Q} & =\text { debit air }\left(\mathrm{m}^{3} / \mathrm{s}\right) \\
\mathrm{V} & =\operatorname{kecepatan} \text { aliran }(\mathrm{m} / \mathrm{s}) \\
\mathrm{A} & =\text { luas penampang pipa }\left(\mathrm{m}^{2}\right)
\end{aligned}
$$

2. Kecepatan aliran (V)

$$
V=\frac{Q}{A}
$$

3. Bilangan Reynold

$$
R e=\frac{\rho \cdot V \cdot D}{\mu}
$$

dimana:

$$
\begin{aligned}
& \mathrm{Re}=\text { Bilangan Reynold } \\
& \boldsymbol{\rho}=\text { Massa Density Air }\left(\mathrm{kg} / \mathrm{m}^{3}\right)
\end{aligned}
$$

$\mathrm{V}=$ Kecepatan Aliran dalam pipa (m/s)

$\mathrm{D}=$ Diameter Pipa $(\mathrm{m})$

$\mu=$ Kekentalan $\left(8,93 \cdot 10^{-4} N . s / m^{2}\right)$

4. Faktor gesekan (f)

Menurut persamaan Hagen - Poiseulle, untuk aliran Turbulen :

$$
f=64 \cdot \frac{\mu}{\rho \cdot V \cdot D}
$$

dimana :

$$
\mu=\text { Kekentalan fluida }\left(8,93 \cdot 10^{-4} N s /\right.
$$

$\left.m^{2}\right)$

$$
\begin{aligned}
& \boldsymbol{\rho}=\text { Massa Density Air }\left(\mathrm{kg} / \mathrm{m}^{3}\right) \\
& \mathrm{V}=\text { Kecepatan Aliran dalam pipa }(\mathrm{m} / \mathrm{s}) \\
& \mathrm{D}=\text { Diameter Pipa }(\mathrm{m})
\end{aligned}
$$

5. Head loss pada pipa (hl pipa)

hl pipa $=$

$f \cdot \frac{L}{D} \cdot \frac{V^{2}}{2 g}$

dimana :

(m)

$$
h l_{\text {pipa }}=\text { kerugian head karena gesekan }
$$

$$
\begin{aligned}
& \mathrm{L}=\text { panjang pipa }(\mathrm{m}) \\
& \mathrm{D}=\text { diameter dalam pipa }(\mathrm{m}) \\
& \mathrm{V}=\operatorname{kecepatan} \text { aliran }(\mathrm{m} / \mathrm{s}) \\
& \mathrm{g}=\text { percepatan gravitasi }\left(\mathrm{m} / \mathrm{s}^{2}\right)
\end{aligned}
$$

6. Head loss pada Elbow/belokan (hl Elbow $_{\text {) }}$

$$
\mathrm{hl}_{\text {Elbow }}=\sum n \cdot K \cdot \frac{V^{2}}{2 g} \text {. }
$$

dimana :

$$
\begin{aligned}
& \mathrm{n}=\text { Jumlah belokan dalam pipa } \\
& \mathrm{K}=\text { faktor gesekan dalam pipa } \\
& \mathrm{V}=\text { Kecepatan Aliran dalam pipa }(\mathrm{m} / \mathrm{s}) \\
& \mathrm{g}=\text { percepatan gravitasi }\left(\mathrm{m} / \mathrm{s}^{2}\right)
\end{aligned}
$$

7. Head loss total

$$
\mathrm{hl} \mathrm{total}=\mathrm{hl}_{\text {pipa }}+\mathrm{hl}_{\text {elbow }}
$$

8. Head elevasi

$$
\mathrm{h} \Delta \mathrm{z}=\mathrm{h} \mathrm{z}_{2}-\mathrm{hz}
$$

dimana:

$$
\begin{aligned}
& \mathrm{h} \Delta \mathrm{z}=\text { Head Elevasi } \\
& \mathrm{hz}_{2}=\text { Sisi Masuk } \\
& \mathrm{hz}_{1}=\text { Sisi Keluar }
\end{aligned}
$$

9. Momen Inersia ( Torque )

Rumus Momen Inersia benda berotasi adalah sebagai berikut :

$$
\tau=\mathrm{m} . \mathrm{r}^{2}
$$

dimana :

$\tau=$ Momen inersia / Torque $\left(\mathrm{kg} \mathrm{m}^{2}\right)$

11 Gunarto, dkk; Model Matematis Turbin Pelton Dengan Menggunakan Bahasa Pemrograman Java 


$$
\begin{aligned}
& \mathrm{m}=\operatorname{massa} / \text { load beban }(\mathrm{kg}) \\
& \mathrm{r}=\operatorname{Jarak}(\mathrm{m})
\end{aligned}
$$

10. Head Turbin

$$
\mathrm{Ht}=P d+\frac{V^{2}}{2 g}-(\text { hl pipa }+ \text { hl elbow })
$$

dimana :

$$
\begin{aligned}
& \mathrm{Ht}=\text { Head Turbin }(\mathrm{m}) \\
& \mathrm{Pd}=\text { Meter kolom air }(\mathrm{mka}) \\
& \mathrm{V}=\text { Kecepatan Aliran dalam pipa }(\mathrm{m} / \mathrm{s}) \\
& \mathrm{g}=\text { percepatan gravitasi }\left(\mathrm{m} / \mathrm{s}^{2}\right)
\end{aligned}
$$

11. Water Horse Power (WHP)

WHP merupakan energi yang dimiliki oleh air dalam bentuk velocity head (head turbin) yang nantinya akan diubah menjadi energi poros.

$$
W H P=\frac{\rho \cdot g \cdot Q \cdot H t}{746} .
$$

dimana :

$$
\begin{aligned}
& \text { WHP = Daya Pompa Air }(\mathrm{kW}) \\
& \mathrm{P}=\text { Density air }\left(1000 \mathrm{~kg} / \mathrm{m}^{3}\right) \\
& \mathrm{g}=\text { Gaya gravitasi }\left(9,8 \mathrm{~m} / \mathrm{s}^{2}\right) \\
& \mathrm{Q}=\text { Debit air }\left(\mathrm{m}^{3} / \mathrm{s}\right) \\
& \mathrm{Ht}=\text { Head Turbin }(\mathrm{m})
\end{aligned}
$$

12. Brake horse power (BHP)

Brake Horse Power (BHP) adalah merupakan daya efektif yang diterima oleh poros turbin dari fluida yang melalui sudu-sudu turbin.

$$
B H P=\frac{P \cdot g \cdot l \cdot 2 \cdot \pi \cdot n}{60.746} .
$$

dimana :

$$
\begin{aligned}
& \text { BHP = Brake horse power } \\
& \mathrm{g}=\text { Percepatan gravitasi }\left(\mathrm{m} / \mathrm{s}^{2}\right) \\
& \mathrm{l}=\text { Panjang pipa }(\mathrm{m}) \\
& \mathrm{n}=\text { Kecepatan putaran turbin }(\mathrm{Rpm})
\end{aligned}
$$

\section{Efesiensi Turbin ( $\eta$ )}

Efisiensi turbin adalah perbandingan antara daya yang dihasilkan pada poros turbin shaft dengan daya yang diberikan oleh fluida fluida

$$
\eta=\frac{B H P}{W H P} \times 100 \%
$$

dimana :

$$
\begin{aligned}
& \eta=\text { Efesiensi Turbin }(\%) \\
& \text { BHP = Brake horse power } \\
& \text { WHP = Water horse power }
\end{aligned}
$$

Berikut adalah spesifikasi dan gambar dari alat praktikum turbin pelton sederhana yang digunakan di Laboratorium Teknik Mesin Universitas Muhammadiyah Pontianak

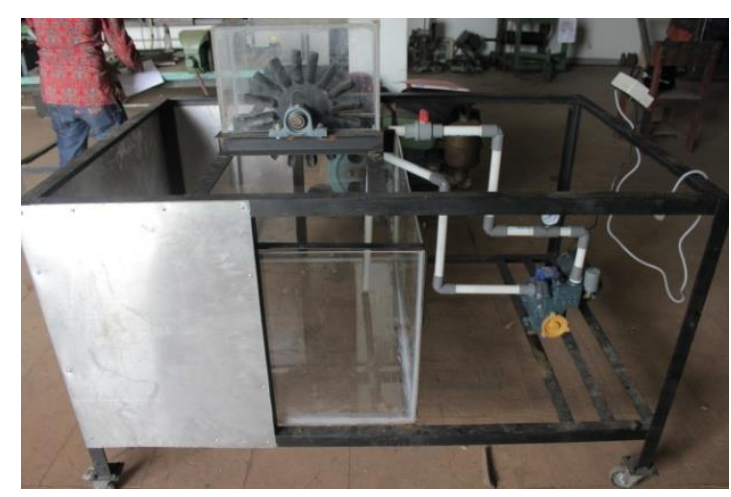

Gambar 2 Model alat Praktikum Turbin Pelton

Spesifikasi alat dan sudu turbin pelton

- Diameter roda jalan (Do) $\quad: 30 \mathrm{~cm}$

- Panjang sudu $\quad: 7 \mathrm{~cm}$

- Lebar sudu $\quad: 11^{1 / 2}$ inchi

- Kedalaman sudu (diameter sudu) $\quad: 0.75$ inchi

- Ketebalan sudu/pipa $\quad: 2 \mathrm{~mm}$

- Diameter pirangan $\quad: 22 \mathrm{~cm}$

- Panjang alat simulasi $\quad: 150$ $\mathrm{cm}$

- Lebar alat simulasi $\quad: 90 \mathrm{~cm}$

- Tinggi alat simulasi $\quad: 80 \mathrm{~cm}$

- Panjang bak penampung air $\quad: 90 \mathrm{~cm}$

- Lebar bak penampung air $\quad: 60 \mathrm{~cm}$

- Tinggi bak penampung air $\quad: 50 \mathrm{~cm}$

- Air di bak penampungan $\quad: 90$ liter

- Kapasitas maksimal pompa air (Q) : 45 $1 /$ menit

- Diameter Nozzle $\quad$ : 15 $\mathrm{mm}$

- $\quad$ Load (beban) P $\quad: 0,7 \mathrm{~kg}$

- Kapasitas Pompa Pompa Air Sentrifugal (Inter Nasional GP200): Spesifikasi: Tipe: Pompa Sumur Dangkal (Otomatis), Daya Hisap : 9 Meter (Max), Daya Output Listrik : 200 watt, Total Head : 35 Meter, Debir Air : 45 liter/menit, Pipa hisap/dorong : 3/4 Inchi.

\section{HASIL DAN PEMBAHASAN}

Secara sederhana sebuah model seharusnya mengikuti rumus atau yang berlaku. Jika terdapat perbedaan presisi perhitungan manual dengan komputer biasa terjadi karena adanya aturan pembulatan. Program yang dirancang dengan menggunakan bahasa pemrograman ini menggunakan aturan 
pembulatan ke atas (ceiling). Berikut sejumlah cuplikan tampilan dari model matematis yang dirancang dengan menggunakan bahasa pemrograman Java seperti yang ditunjukkan pada Gambar 3.

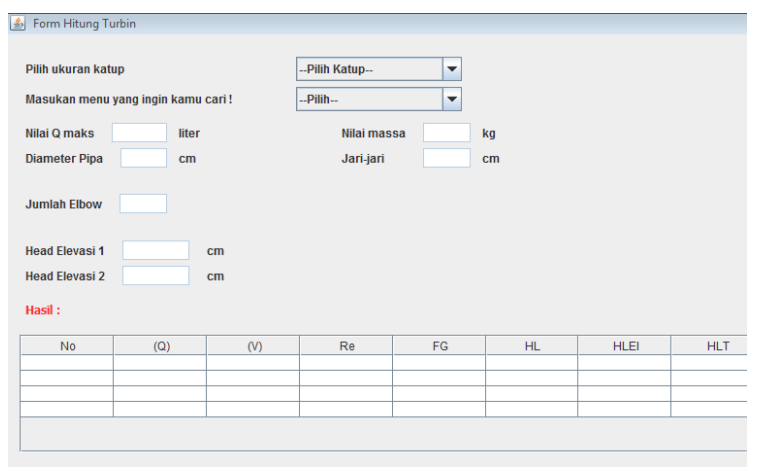

\section{Gambar 3 Tampilan menu utama dari aplikasi}

Karena dasar dari pembuatan aplikasi ini didasarkan pada rumus - rumus yang telah disebutkan diatas, maka ada tiga percobaan yang dilakukan. Untuk percobaan 1, dapat ditunjukkan pada Gambar 4.

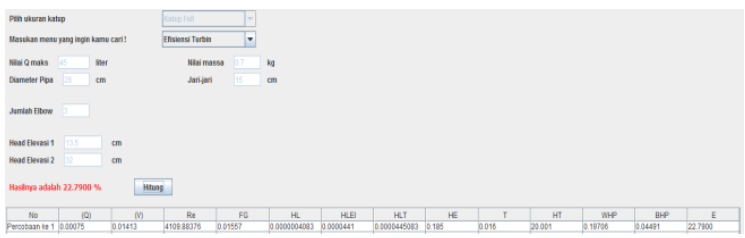

\section{Gambar 4 Hasil percobaan 1 untuk katup} full

Sejumlah source code untuk menampilkan nilai yang ada di dalam tabel dapat ditunjukkan pada Gambar 5.

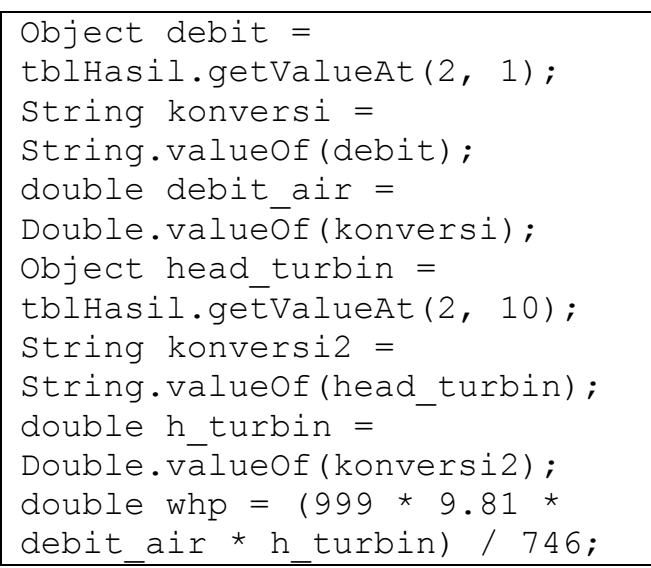

Dari Gambar 4, 6, dan 7 jelas terdapat antara katup yang dibuka full, $1 / 2$ dan $1 / 4$. Katup yang dibuka $1 / 4$ menghasilkan efisiensi paling besar dibandingkan katup yang full dan 1/2. Hal

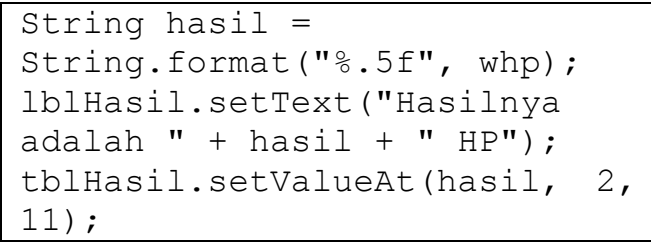

\section{Gambar 5 Cuplikan kode di Java untuk perhitungan WHP}

Dari Gambar 5 dapat terlihat rumus Water Horse Power (WHP) sesuai dengan aturan rumus nomor double whp $=(999 * 9.81$ * debit air * $\mathrm{h}$ turbin) / 746;

Percobaan kedua adalah ketika katup dibuka sebesar $1 / 2$ seperti yang ditunjukkan pada Gambar 6 .

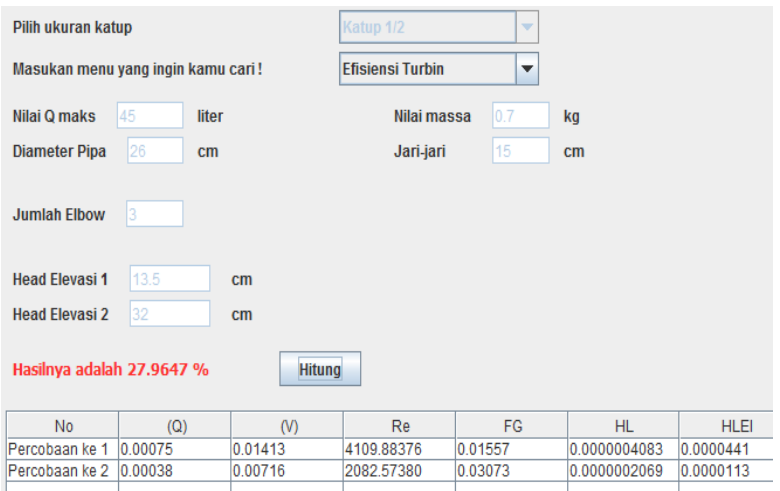

\section{Gambar 6 Tampilan program untuk percobaan katup 1/2}

Percobaan ketiga adalah ketika katub dibuka sebesar 1/4. Maka didapatkan hasil pergitungan dengan program seperti yang ditunjukkan pada Gambar 7.

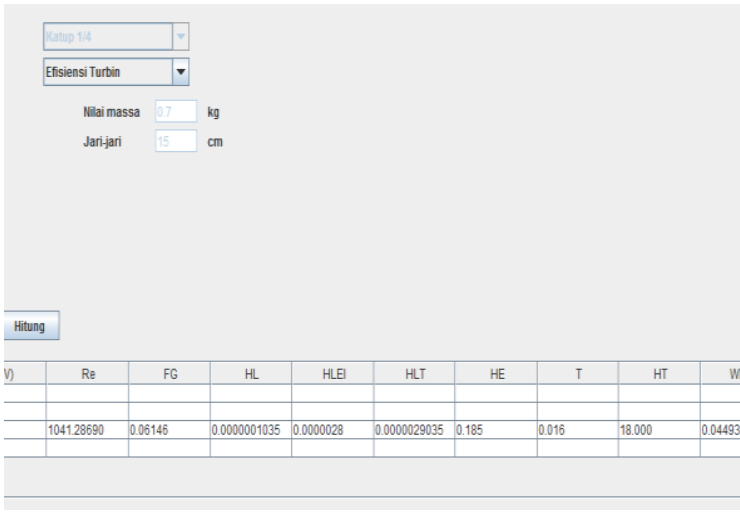

\section{Gambar 7 Tampilan program untuk percobaan katup 1/4}

ini dikarenakan perbedaan WHP dan BHP yang besar membuat katup $1 / 4$ mendapatkan efisiensi yang paling besar. 


\section{KESIMPULAN}

Kesimpulan dari penelitian ini adalah:

1. Program ini sudah bisa digunakan untuk mengelola data yang diperoleh dari pengambilan data praktikum turbin pelton

2. Program ini secara sederhana dapat dengan cepat membantu proses perhitungan dan pengolahan nilai-nilai hasil dari praktikum turbin pelton

3. Meskipun program ini bisa dijalankan tetapi masih banyak kekurangannya, oleh karena itu program ini bisa dikembangkan lebih lanjut untuk perhitungan yang lebih rinci dan detail.

4. Program ini bisa dengan mudah digunakan oleh pengguna karena hanya tinggal memasukkan nilai-nilai yang sudah di dapat ke dalam program.

\section{REFERENSI}

[1] Bruner, J.S. 1966. Toward a Theory of Instruction. New York: Norton

[2] Eko Kurniawan Kannedy, 2011, Belajar Bahasa Java Dasar, StripBandunk

[3] Gunarto dkk, 2017, Rekayasa Model Peralatan Praktikum Turbin Pelton Dengan Type Sudu Setengah Silinder, Jurnal
MACHINE Vol. 3 No.1 Januari 2017, Teknik Mesin Universitas Bangka Belitung

[4] Ifnu Bima, 2008, Materi Pelatihan Java Dekstop, Artivisi Intermedia, http://ifnu.artivisi.com

[5] Ifnu Bima, 2011, Java Dekstop, Aplikasi POS Ber Aplikasi POS Berarsitektur Three Tier Menggunakan Swing, Hibernate dan Spring, ifnubima.org

[6] Mc.Guinness J. William, Stein Benjamin. 1979. Mechanical and Electrical Equipment for Buildings. New York. John Willey and Sons,Inc.

[7] MunsonBruce R. 2002. Fundamental of Fluid Mechanics, John Wiley \& Sons, Inc, United States of America

[8] Romi Satria Wahono,2010, OOP: Java GUI with Neatbeans, http://romisatriawahono.net

[9] Sularso, Haruo Tahara. 1987. Pompa dan Kompresor. Jakarta, PT Pradnya Paramita.

[10] Suparman, Atwi. 1993. Desain Intruksional. Jakarta: PAU untuk Peningkatan dan Pengembangan Aktivitas Instruksional Dirjen Dikti

[11]Tyler G.Hicks, T.W.Edwards, Zulkifli Harahap. 1996. Teknologi Pemakaian Pompa. Jakarta, Penerbit Erlangga.

[12] Wibowo Paryatmo,2007, Turbin Air, Edisi Kedua,Yogyakarta Penerbit Graha Ilmu 